Supporting Information

for the article entitled

\title{
Vanadium-Catalyzed Cross Metathesis: Limitations and Implications for Future Catalyst Design
}

authored by

\author{
Wesley S. Farrell* \\ Chemistry Department, United States Naval Academy, 572M Holloway Rd, Annapolis, MD 21402 \\ E-mail: wfarrell@usna.edu
}




\section{EXPERIMENTAL DETAILS}

General. All air and moisture sensitive manipulations were carried out under nitrogen using standard glovebox or Schlenk-line techniques. Benzene, pentane, hexane, and tetrahydrofuran (THF) were distilled under nitrogen from sodium/benzophenone. Dichloromethane (DCM) was distilled from calcium hydride under nitrogen. Benzene- $d_{6}$, 1-hexene, cis-4-octene, and allyltrimethylsilane were stirred over sodium/potassium alloy, degassed, and isolated by transfer under static vacuum. Allylbenzene was distilled from sodium under reduced pressure. Ethylene (>99.5\%) was purchased from Sigma-Aldrich and used as received. Compounds $\mathbf{1}$ and $\mathbf{2}$ were prepared as described in the literature. ${ }^{1}$ All other reagents were used as received. Nuclear magnetic resonance (NMR) spectroscopy was performed using a JEOL $400 \mathrm{MHz}$ spectrometer. ${ }^{1} \mathrm{H}$ NMR spectra were referenced to the residual solvent signal (7.26 ppm for chloroform- $d, 7.16 \mathrm{ppm}$ for benzene- $d_{6}$ ).

Self Metathesis Reactions. A 1 dram vial was charged with the prescribed amount of compound $\mathbf{1}$ or 2 and a magnetic stir bar, and was placed within a 4 dram vial. Solvent, if any, was added via syringe. The terminal olefin was added in the proper amount via syringe. The vial was capped and allowed to stir at room temperature or with heating for the prescribed amount of time. An aliquot was removed and quenched by addition of unpurified chloroform- $d$ under air and analyzed immediately by ${ }^{1} \mathrm{H}$ NMR for conversion and $E: Z$ ratio determinations. Conversions were determined by comparing the integrals of the $\mathrm{CH}_{2}$ olefinic proton resonances of the starting terminal olefins to the $\mathrm{CH}$ olefinic resonances of the target homocoupled product ( $E$ and $Z$ ). The remaining material was dissolved in unpurified pentane under air, combined with the aliquot, filtered through a plug of silica gel, and volatiles were removed in vacuo until no change in mass was observed to obtain the yield.

\section{NMR Experiments.}

- SM of 1-hexene. A J. Young NMR tube equipped with a Teflon seal was charged with $\mathbf{1}(0.004 \mathrm{~g}$, $6 \mu \mathrm{mol})$ and $0.6 \mathrm{~mL}$ benzene- $d_{6}$. 1 -Hexene $(15.0 \mu \mathrm{L}, 120 \mu \mathrm{mol})$ was added via syringe. ${ }^{1} \mathrm{H}$ NMR recorded immediately demonstrated that ethylene gas and 5-decene had formed. No resonances for compound 1 nor any other vanadium species could be found by either ${ }^{1} \mathrm{H}$ or ${ }^{51} \mathrm{~V}$ NMR. Allowing the reaction to continue overnight led to no increase in conversion. See Figures S6 - S7 for ${ }^{1} \mathrm{H}$ NMR spectra.

- Cis/trans isomerization of cis-4-octene. A J. Young NMR tube equipped with a Teflon seal was charged with $1(0.011 \mathrm{~g}, 16 \mu \mathrm{mol})$ and $0.6 \mathrm{~mL}$ benzene- $d_{6}$. $c i s-4$-Octene $(5.0 \mu \mathrm{L}, 32 \mu \mathrm{mol})$ was added via syringe. The tube was allowed to react at room temperature, and ${ }^{1} \mathrm{H}$ NMR were recorded periodically. Slow isomerization if cis-4-octene was observed. See Figures $\mathrm{S} 8$ - S9 for ${ }^{1} \mathrm{H}$ NMR.

- Reaction of 1 with ethylene (qualitative). A J. Young NMR tube equipped with a Teflon seal was charged with $1(0.007 \mathrm{~g}, 10 \mu \mathrm{mol})$ and $0.6 \mathrm{~mL}$ benzene- $d_{6}$, and an initial ${ }^{1} \mathrm{H}$ NMR spectrum was recorded. The headspace was evacuated and charged with ethylene (10 psi). ${ }^{1} \mathrm{H}$ NMR immediately revealed complete decomposition of $\mathbf{1}$, as well as the presence of vinyltrimethylsilane and propylene (Figure S10).

- Reaction of 1 with ethylene (quantitative). A J. Young NMR tube equipped with a Teflon seal was charged with $1(0.024 \mathrm{~g}, 36 \mu \mathrm{mol})$, durene as an internal standard $(0.002 \mathrm{~g}, 15 \mu \mathrm{mol})$, and 1.8 $\mathrm{mL}$ benzene- $d_{6}$, and an initial ${ }^{1} \mathrm{H}$ NMR spectrum was recorded. (Note: The reason that such a large volume of benzene- $d_{6}$ was employed was to minimize the headspace, thus minimizing the volume to which propylene could escape.) The headspace was evacuated and charged with ethylene (10 psi). ${ }^{1} \mathrm{H}$ NMR immediately revealed complete decomposition of $\mathbf{1}$, as well as the 
presence of vinyltrimethylsilane and propylene (Figure S11 - S12). Integration determined that propylene was formed in $43 \%$ yield (see below for calculations). This value should be viewed as a lower limit for $\beta$-hydride elimination, given that propylene certainly escaped to the headspace of the sealed NMR tube.

- Calculation: In the initial ${ }^{1} \mathrm{H}$ NMR, the durene aryl signals $(2 \mathrm{H})$ and compound $\mathbf{1}$ meta aryl signals $(2 \mathrm{H})$ were integrated. The durene aryl signals were normalized to 1.00 , giving an integral value of 1.42 for the meta aryl signals for $\mathbf{1}$. This established a 1.00:1.42 ratio for durene to $\mathbf{1}$. After reaction with ethylene, the durene aryl signal $(2 \mathrm{H})$ and propylene methyl signal $(3 \mathrm{H})$ were integrated. A $100 \%$ yield of propylene is expected to show an integral of 2.13 when the durene aryl signals are normalized to 1.00 based on the $2 \mathrm{H}: 3 \mathrm{H}$ ratio of durene aryl protons to propylene methyl protons. The measured integral for the propylene methyl protons was found to be 0.91 , establishing that propylene is present in solution in $43 \%$ yield.

\section{REFERENCES}

(1) Chaimongkolkunasin, S.; Nomura, K. (Arylimido)Vanadium(V)-Alkylidenes Containing Chlorinated Phenoxy Ligands: Thermally Robust, Highly Active Catalyst in Ring-Opening Metathesis Polymerization of Cyclic Olefins. Organometallics 2018, 37, 2064-2074. 


\section{SUPPORTING SPECTRA}

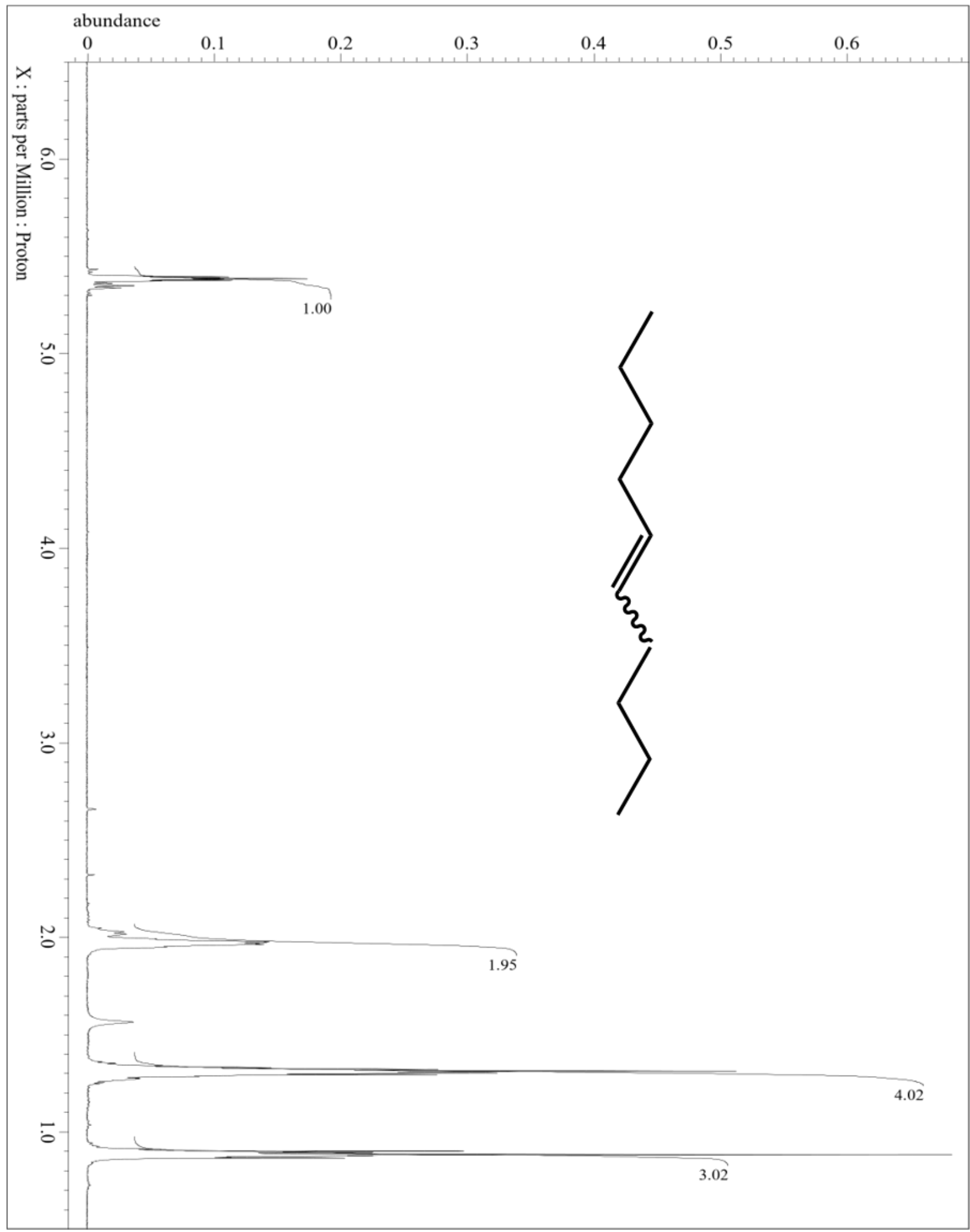

Figure S1. Representative ${ }^{1} \mathrm{H}\left(400 \mathrm{MHz}\right.$, chloroform- $\left.d, 25^{\circ} \mathrm{C}\right)$ NMR of isolated products from homocoupling of 1hexene using 1. 


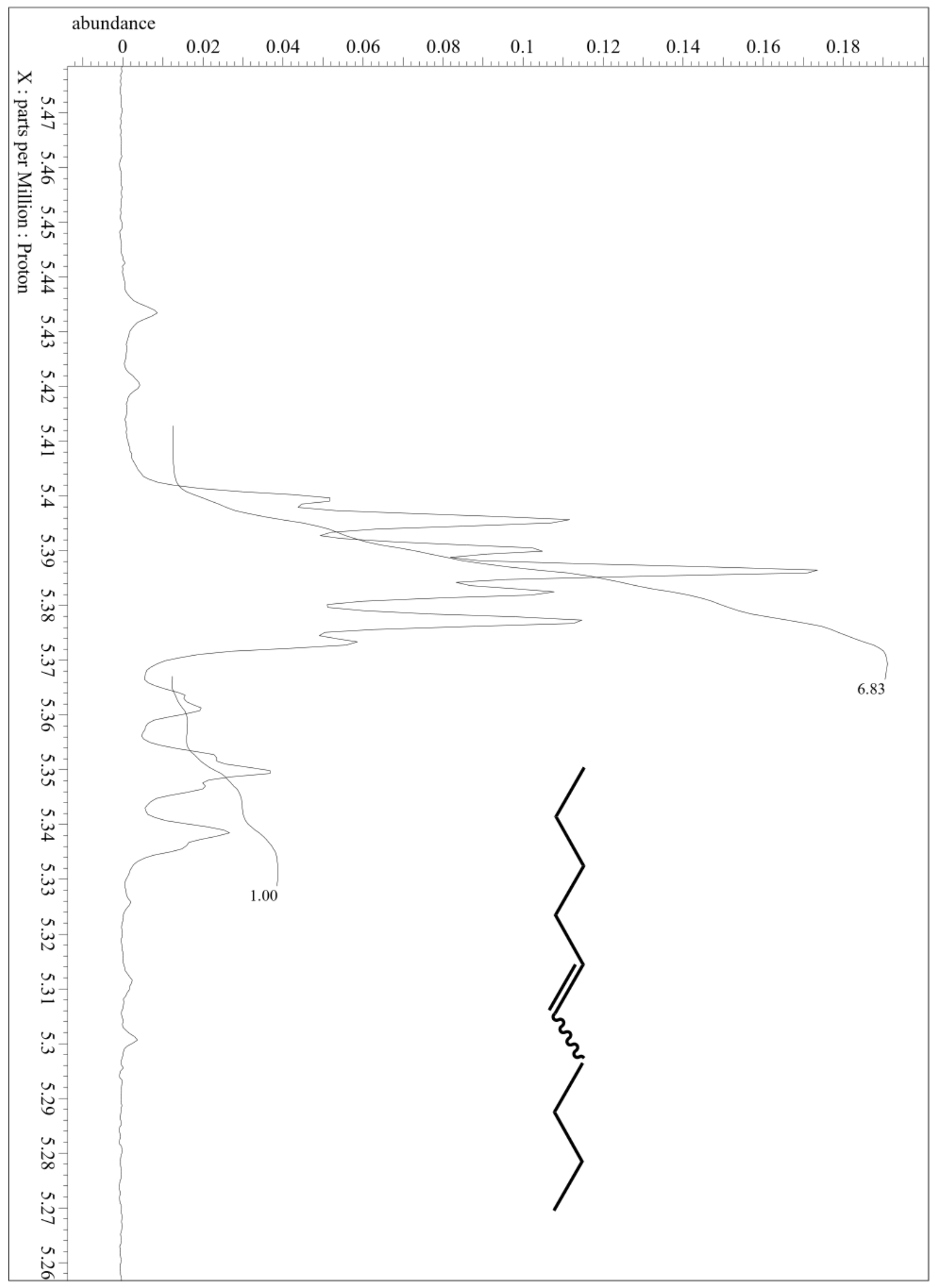

Figure S2. Representative olefinic region of ${ }^{1} \mathrm{H}\left(400 \mathrm{MHz}\right.$, chloroform- $\left.d, 25^{\circ} \mathrm{C}\right)$ NMR of isolated products from homocoupling of 1-hexene using 1. 


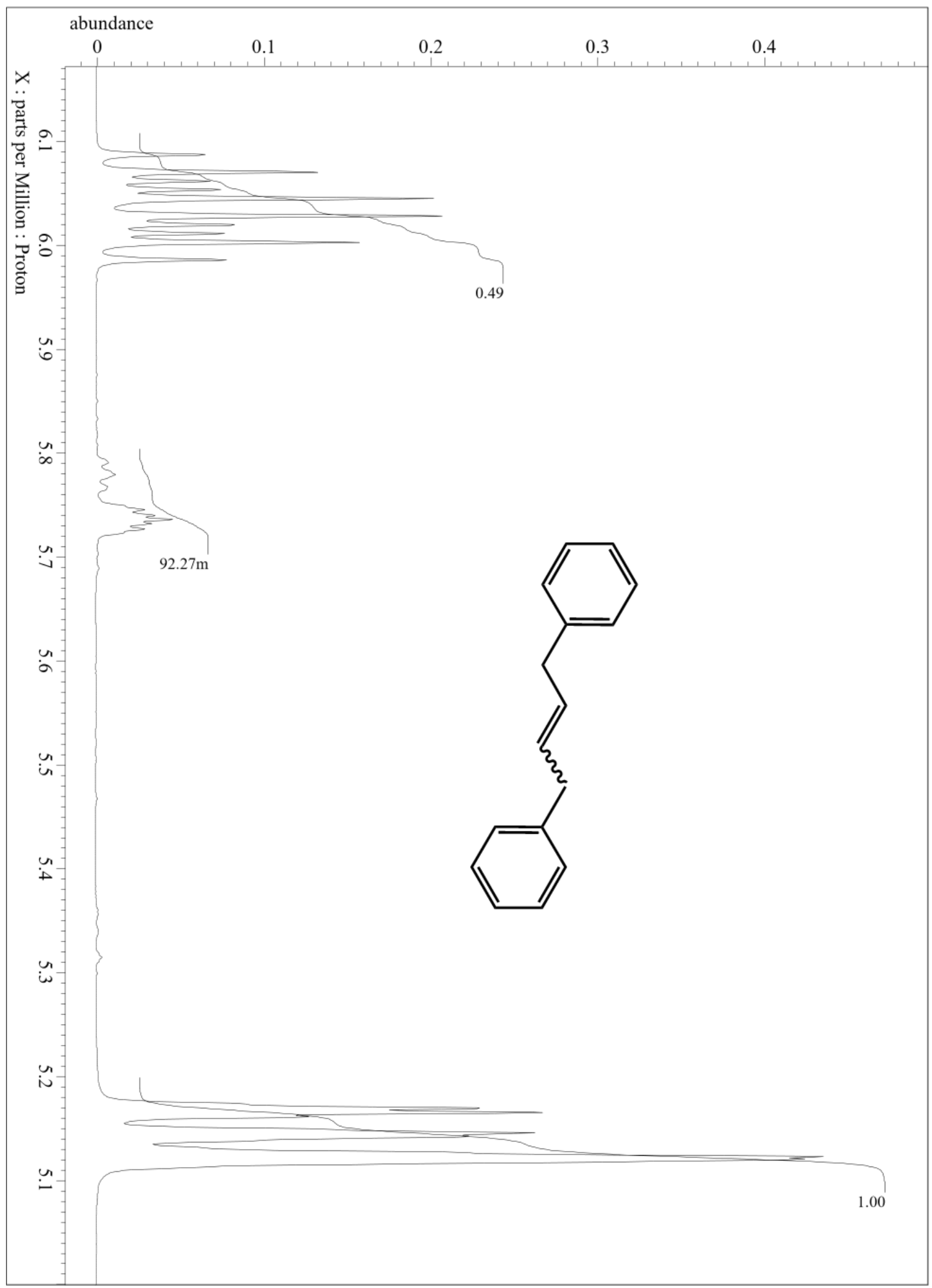

Figure S3. Representative olefinic region of ${ }^{1} \mathrm{H}\left(400 \mathrm{MHz}\right.$, chloroform- $\left.d, 25^{\circ} \mathrm{C}\right) \mathrm{NMR}$ of aliquot taken from homocoupling of allylbenzene using $\mathbf{1}$. 


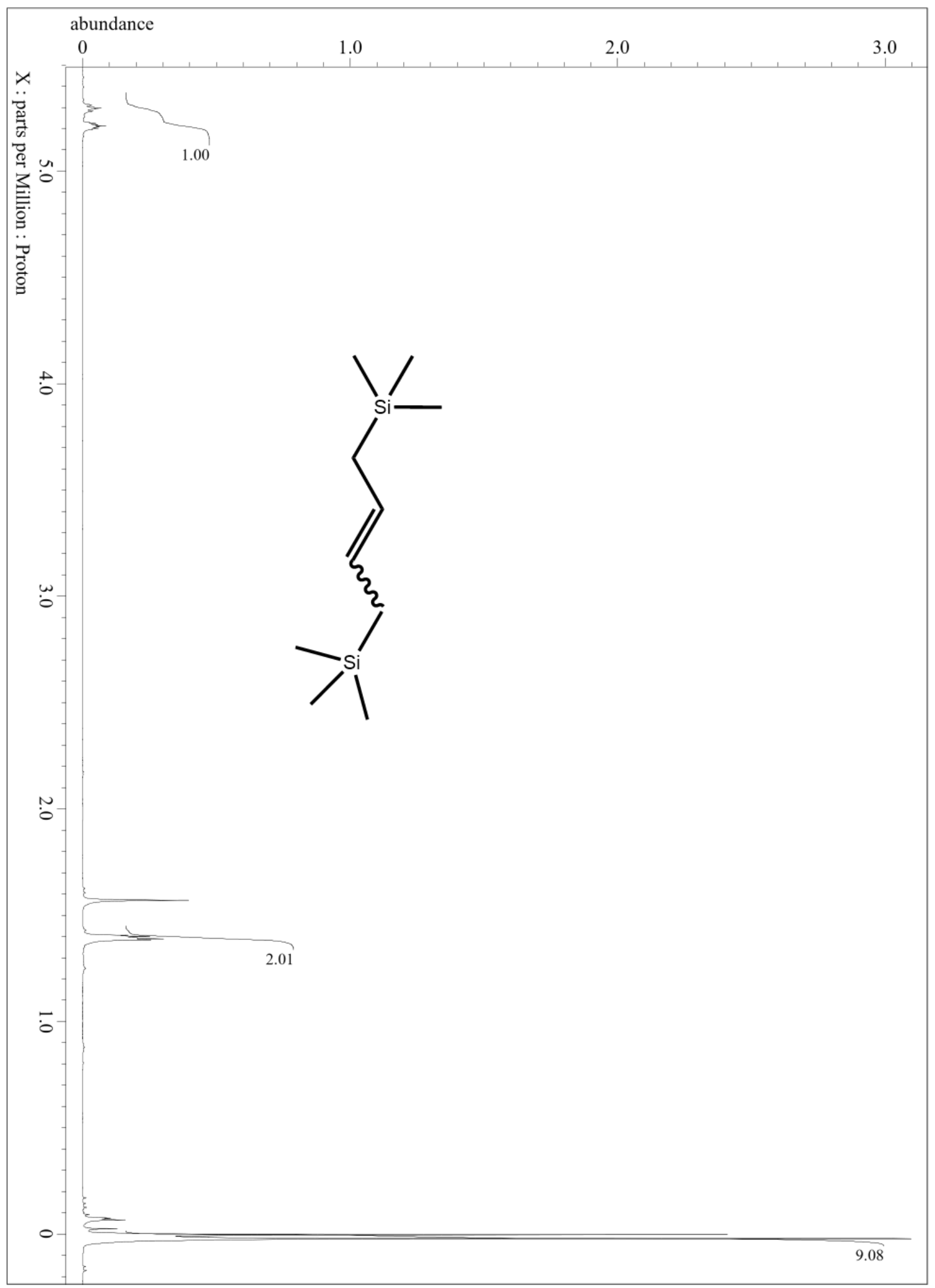

Figure S4. Representative ${ }^{1} \mathrm{H}$ ( $400 \mathrm{MHz}$, chloroform- $d, 25^{\circ} \mathrm{C}$ ) NMR of isolated products from homocoupling of allyltrimethylsilane using $\mathbf{1}$. 


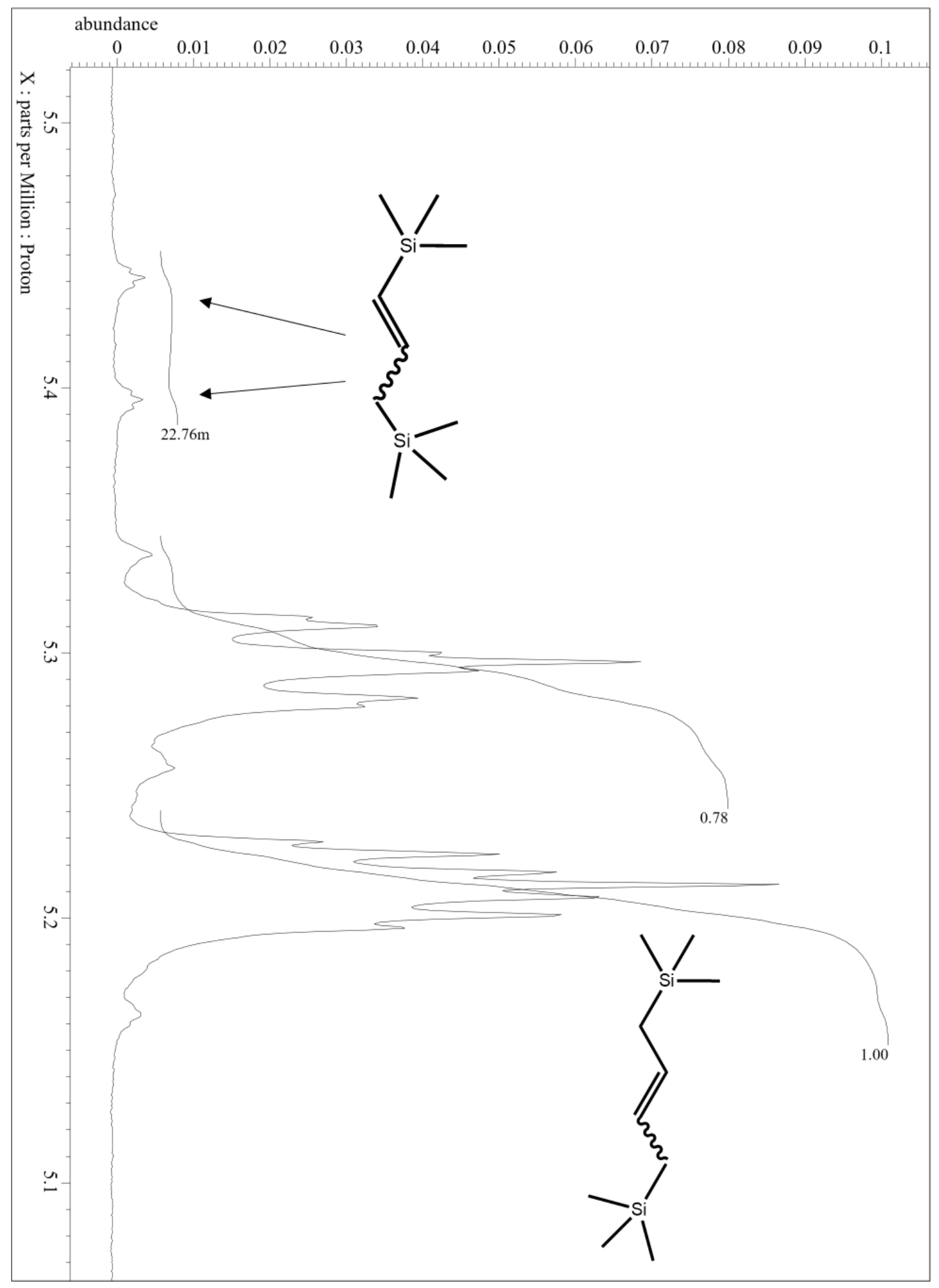

Figure S5. Representative olefinic region of ${ }^{1} \mathrm{H}\left(400 \mathrm{MHz}\right.$, chloroform- $\left.d, 25^{\circ} \mathrm{C}\right)$ NMR of isolated products from homocoupling of allyltrimethylsilane with $\mathbf{1}$. 


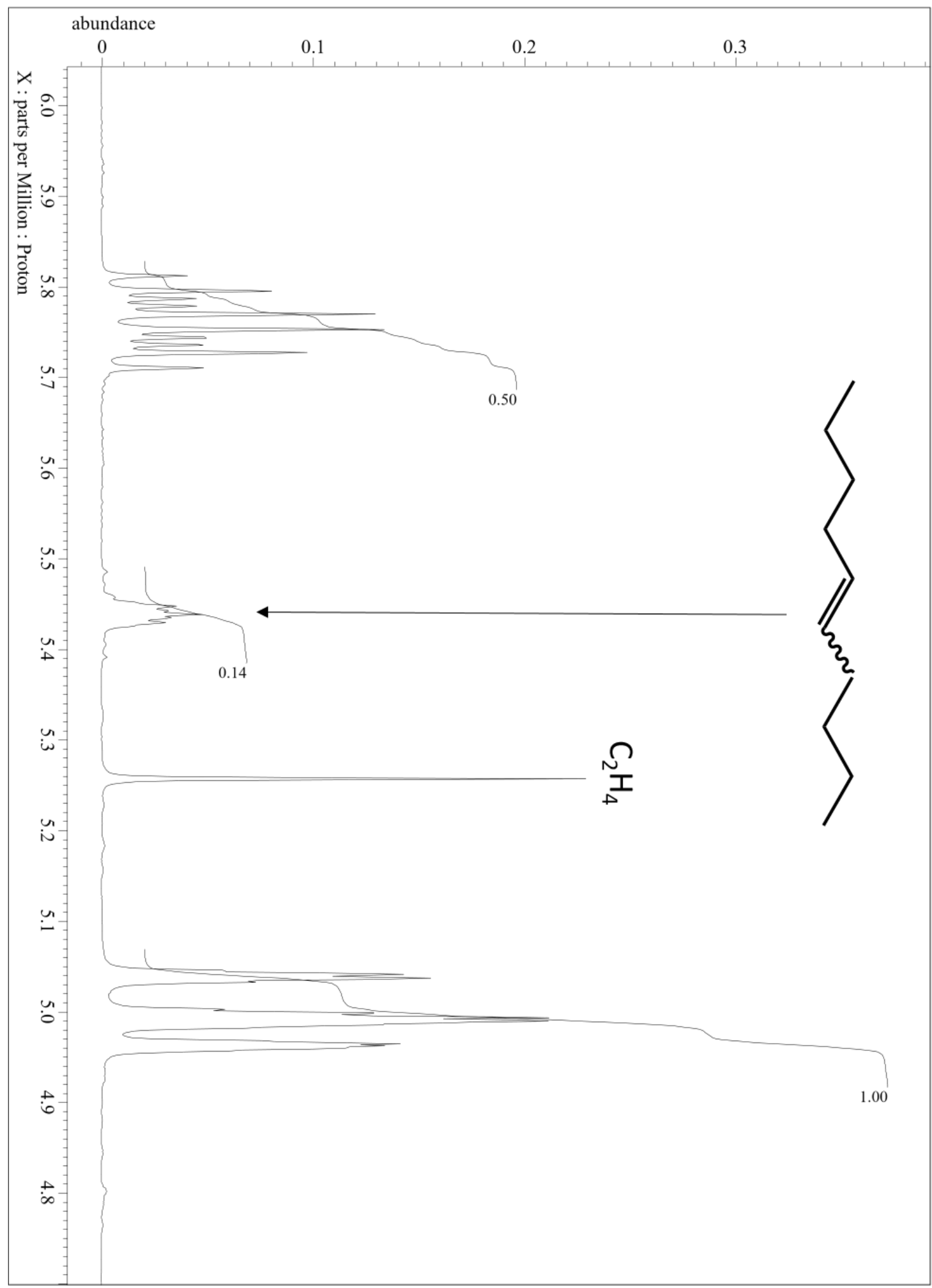

Figure S6. Olefinic region of ${ }^{1} \mathrm{H}\left(400 \mathrm{MHz}\right.$, benzene- $\left.d_{6}, 25^{\circ} \mathrm{C}\right)$ NMR of homocoupling of 1-hexene by compound 1 performed in J. Young NMR tube (initial spectrum, no change was observed after longer reaction times, predominant, unlabeled resonances are 1-hexene). 


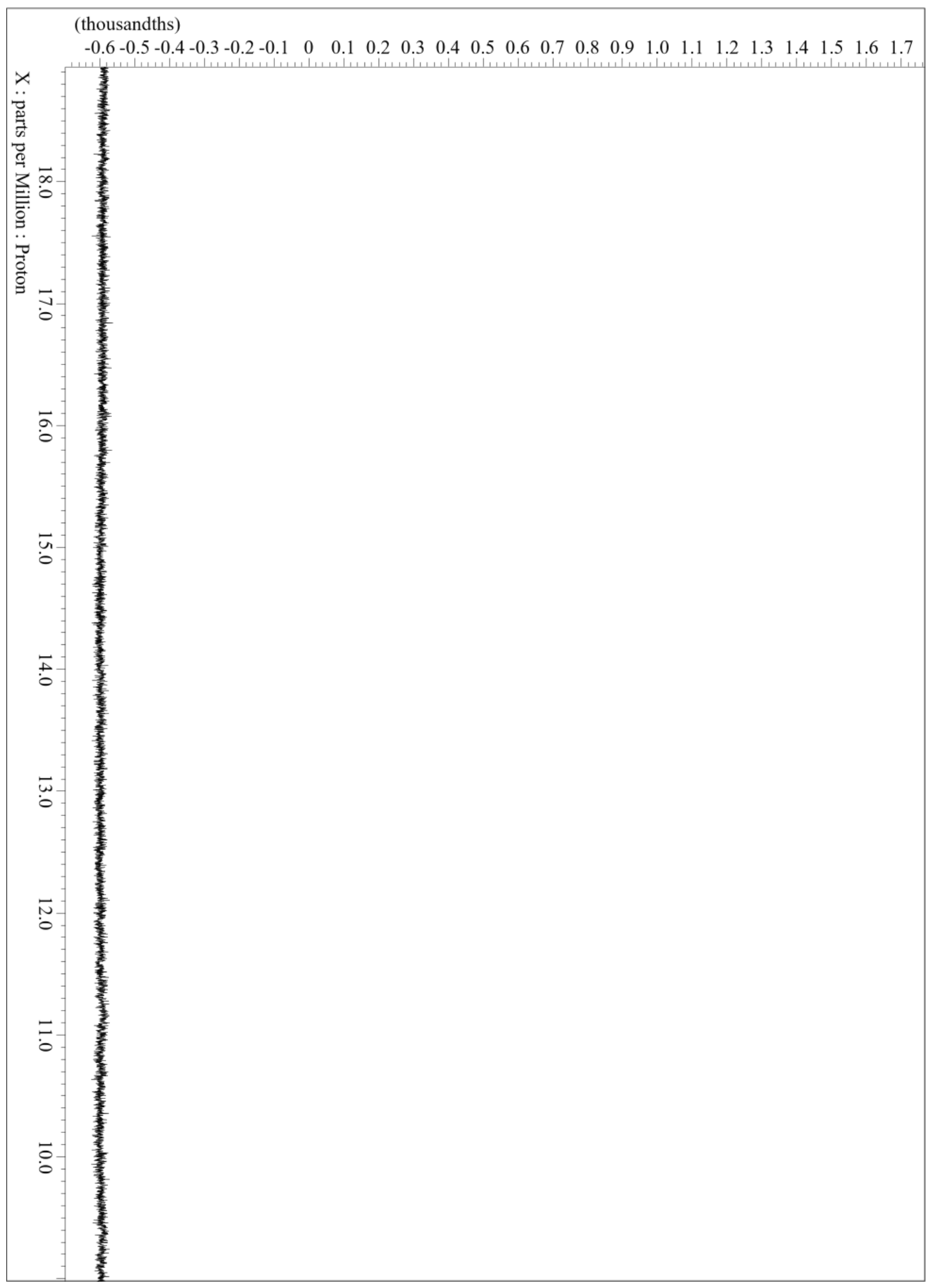

Figure S7. Alkylidene region of ${ }^{1} \mathrm{H}\left(400 \mathrm{MHz}\right.$, benzene- $\left.d_{6}, 25^{\circ} \mathrm{C}\right) \mathrm{NMR}$ of homocoupling of 1-hexene by compound 1 performed in J. Young NMR tube (initial spectrum, no change was observed after longer reaction times). 


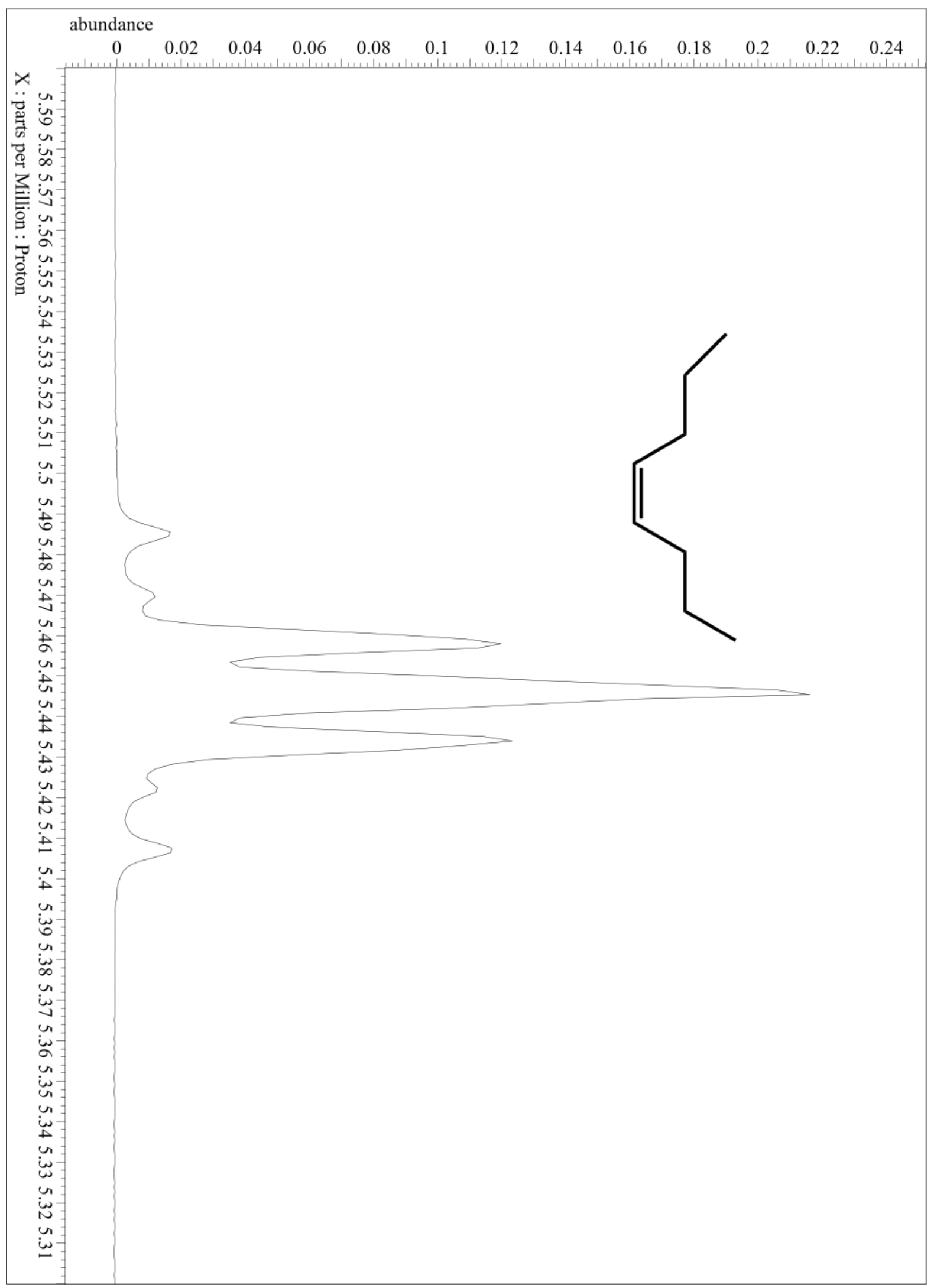

Figure S8. Olefinic region of initial ${ }^{1} \mathrm{H}\left(400 \mathrm{MHz}\right.$, benzene- $\left.d_{6}, 25{ }^{\circ} \mathrm{C}\right) \mathrm{NMR}$ of reaction of 1.with cis-4-octene. 


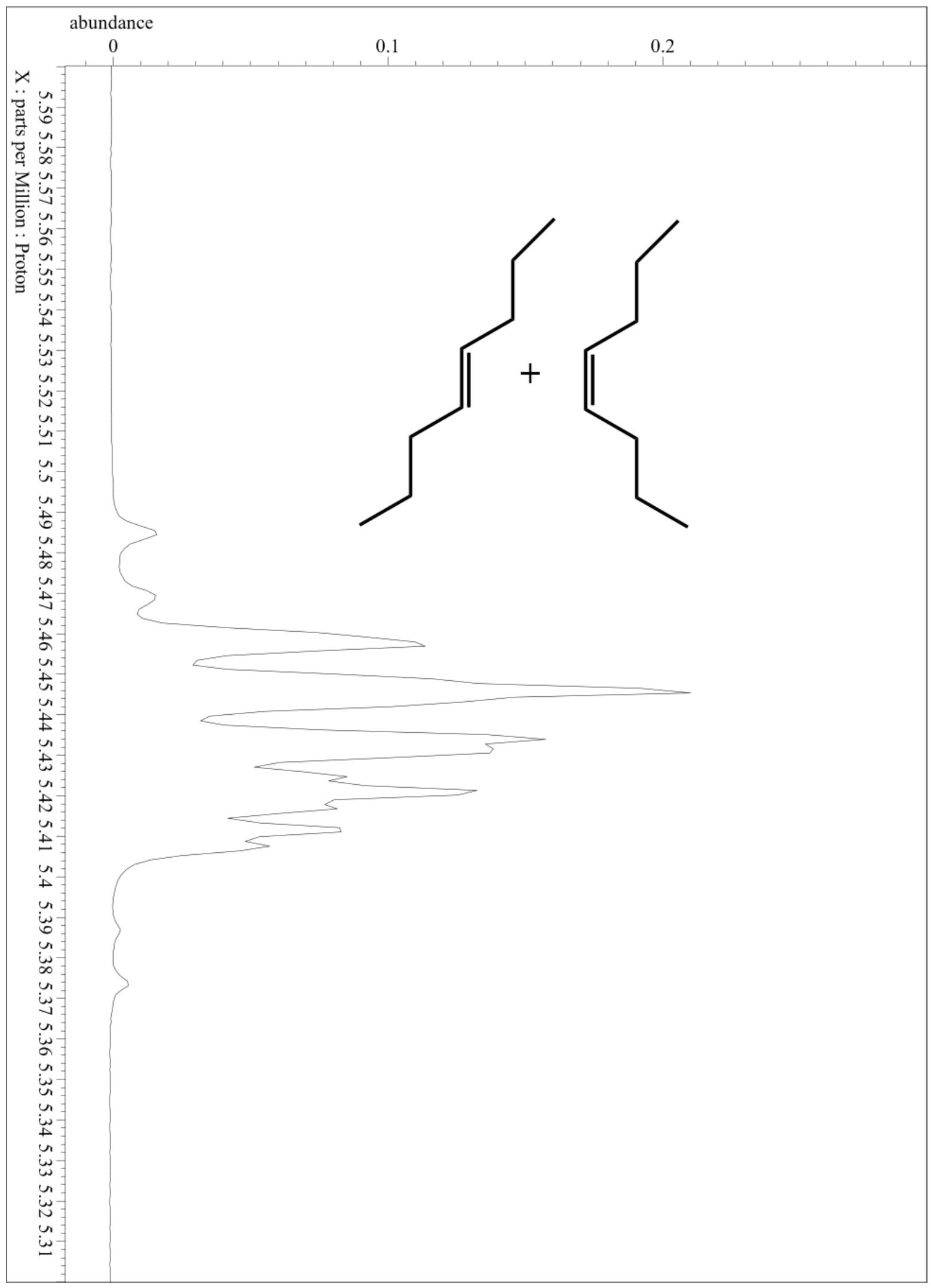

Figure S9. Olefinic region of ${ }^{1} \mathrm{H}\left(400 \mathrm{MHz}\right.$, benzene- $\left.d_{6}, 25^{\circ} \mathrm{C}\right) \mathrm{NMR}$ of reaction of 1 with cis-4-octene after $13 \mathrm{~h}$ at room temperature. 


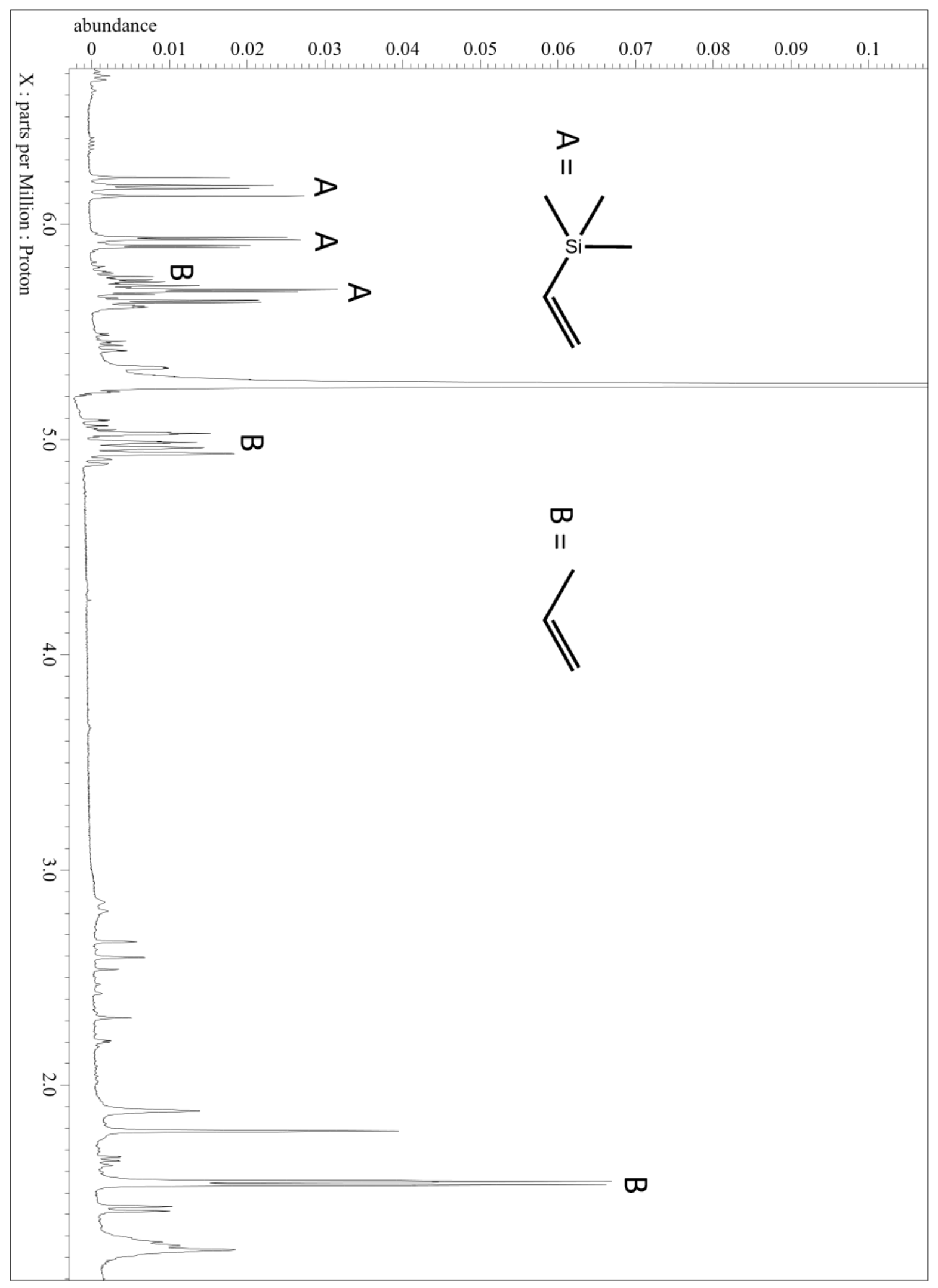

Figure S10. Partial, initial ${ }^{1} \mathrm{H}\left(400 \mathrm{MHz}\right.$, benzene- $\left.d_{6}, 25^{\circ} \mathrm{C}\right)$ NMR of reaction of 1 with ethylene at room temperature (qualitative experiment). 


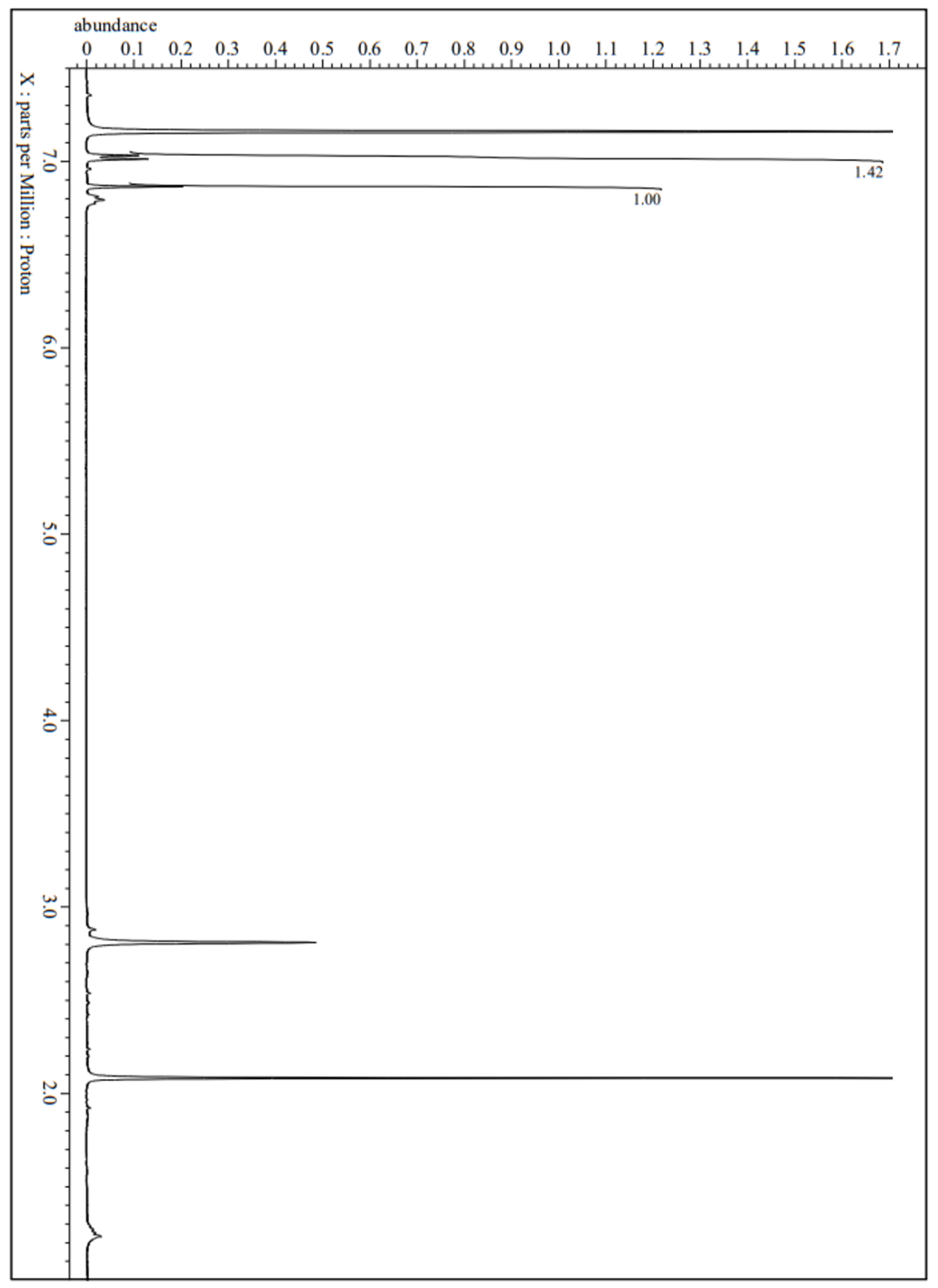

Figure S11. Partial, initial ${ }^{1} \mathrm{H}\left(400 \mathrm{MHz}\right.$, benzene- $\left.d_{6}, 25^{\circ} \mathrm{C}\right) \mathrm{NMR}$ of 1 before reaction with ethylene (quantitative experiment). Durene ( $\delta 6.85 \mathrm{ppm}, 2.10 \mathrm{ppm})$ included as internal standard. 


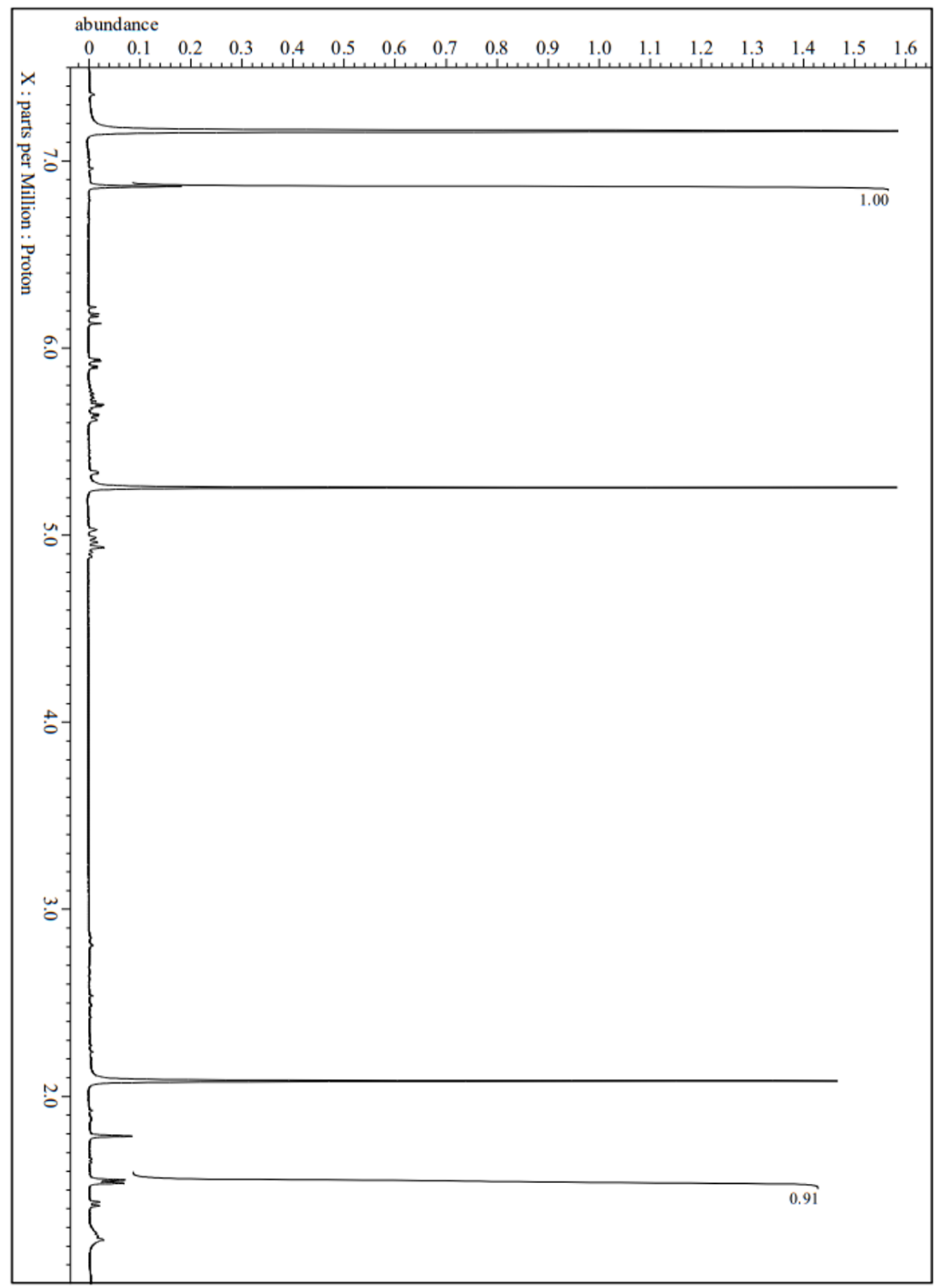

Figure S12. Partial, initial ${ }^{1} \mathrm{H}\left(400 \mathrm{MHz}\right.$, benzene- $\left.d_{6}, 25^{\circ} \mathrm{C}\right) \mathrm{NMR}$ of 1 after reaction with ethylene (quantitative experiment). Durene ( $\delta 6.85 \mathrm{ppm}, 2.10 \mathrm{ppm})$ included as internal standard. 